\title{
UNDERGRADUATE STUDENTS' INVOLVEMENT IN DIGITAL PATIENT-EDUCATION STRATEGY AMID COVID-19 PANDEMIC
}

\author{
Mayoral-Peña $\mathrm{K}^{1^{*}}$, Hambleton-Fuentes $\mathrm{A}^{1^{*}}$ and Caloca-Lafont $\mathrm{E}^{2^{*}}$ \\ ${ }^{1}$ Tecnologico de Monterrey, School of Medicine and Health Sciences (TecSalud) Mexico \\ ${ }^{2}$ Universidad Nacional Autónoma de México (UNAM), University Program of Studies on \\ Democracy, Justice and Society (PUEDJS) / Tecnológico de Monterrey, School of Humanities \\ and Education (EHE)
}

\begin{abstract}
The COVID-19 pandemic generated relevant challenges in educating future physicians and brought attention back to the vulnerability caused by non-communicable diseases (NCDs), such as cancer, emphysema, and cardiovascular affections. Due to the risk of the 2019 Coronavirus contagion, the patient-based education strategies were put on hold, as they were face-to-face. Also, there was an urgent need to develop strategies that used new technologies to offer efficient and fast medical content to the non-specialized public. To overcome this situation, we involved undergraduate students of medicine in developing scientific content and infographics about the prevention and early diagnosis of cancer for a mobile application. The objective of this study was to assess the learning impact generated by the creation of digital patient-education materials. Five medical students enrolled in the Pathophysiology of Respiratory System course at Tecnologico de Monterrey were recruited as participants in the educational strategy with weekly sessions for four months. The following pedagogical tools were used during the intervention: project-based learning, challenge-based learning, engagement, service learning, science outreach, design thinking, and mentoring. Ten infographics for the mobile application were created after this experience. Also, a qualitative and transversal analysis of the undergraduates' learning was implemented using a focus group session as an instrument to evaluate the mentioned strategy's impact. As a relevant finding, we observed a high level of engagement, improvement in communication skills, and ethical reflections among the students. After the app is completed, we plan to create a social startup to generate more content about NCDs to promote prevention and early diagnosis. Educational strategies involving medical undergraduates in social projects have two beneficial outcomes: the student internalizes significant knowledge and positively impacts society's health. This project aims to inspire educators to empower students to develop real-life solutions as part of their college activities.
\end{abstract}

Keywords: Educational innovation, medical education, patient-education strategy, digital technology development, pandemic adaptations, cancer education

\section{Introduction}

During the first months of the COVID-19 pandemic, training the population on the risks of contagion from this infectious disease was a priority. Health and academic institutions focused on designing content and materials about preventing contagion, general care, outpatient management, and vaccine application. However, the prevention and care of non-communicable diseases, such as cancer and diabetes, was relegated to the background. Medical students' role in disseminating preventive 
strategies through different channels, including social media and instant messaging (IM) platforms, has been invaluable. During the current pandemic, the medicine and health sciences departments needed to enforce social responsibility in their students. As a result, many health professionals in training and teachers contributed to educate and support people affected by this situation (ValdezGarcía et al., 2020).

The training of undergraduate medical students includes a series of activities that help to develop their professional capabilities. Because of the pandemic, many of these activities had to be replaced by online conferences, virtual simulation scenarios, and asynchronous activities. However, critical tasks that support the construction of knowledge and apply learning processes that link students to their reality are required. In recent decades, it has been shown that active learning favors the retention of knowledge beyond simple memorization. Also, it generates a learning process that is more meaningful, flexible, and durable (Baepler et al., 2016).

Medical schools' educational environment is complex and has different nuances, determined by geographical, cultural, and material aspects and human resources. These learning spaces influence how medical students develop their professional skills. Most medical training programs are divided into preclinical and clinical stages, where the learning moments close to the patient are usually present in the last learning stage. Contact with patients, teaching strategies, and student's perception of the environment have a relevant impact on undergraduates' academic development, skills acquisition, and physical and emotional well-being (Lafuente-Sanchez, 2019).

Literature shows that students have greater motivation in constructing their learning when they participate in a creative, autonomous, and collaborative environment during the development of projects. Project learning works best when the objectives are well-defined, and the students have specific actions to perform (Sanmartí and Márquez, 2017). These strategies allow future professionals to acquire knowledge that can be used in personal, local, and global scenarios. During the learning process, undergraduate medical students require mentoring to develop competencies and overcome stressful situations. Having a mentor who asks questions, supervises, and listens can be critical for maintaining mentees' academic and personal integrity and developing their problem-solving and decision-making skills (Usmani, Omaeer, and Sultan, 2011).

Infographics design is a learning tool that allows students to develop communication skills and promote critical thinking because it requires combining visual elements and sending a specific message (Jones Sage and Hitchcock, 2019). According to the topics selected for infographics, students assimilate processes and concepts of varying complexity and learn how to explain them in concise and basic terms (Dunlap and Lowenthal, 2016; Martin et al., 2019).

According to the World Health Organization (WHO), cancer reached more than 19 million people worldwide in 2020; therefore, it became the second leading cause of death in the Americas. The most common diagnoses of this disease were prostate, breast, lung, and colorectal cancers (WHO, 2021). The implementation of early detection procedures improves morbidity rates and saves many people's lives. The burden of cancer can be reduced by implementing strategies for prevention, screening, early detection, treatment, and palliative care. The most common modifiable risk factors for cancer are the 
same as those of other non-communicable diseases (NCDs), so it is possible to reduce their incidence using community education strategies to promote a healthy lifestyle and early detection ${ }^{1}$.

This study aimed to assess the learning impact of generating digital patient-education materials by undergraduate medical students (Figure 1). This exploratory strategy was created as a part of a social project that consisted of developing a mobile application for patients useful for prevention and early cancer diagnosis. The students were able to create the contents of the mentioned application using infographics as a format. During the intervention, the pedagogical tools used were project-based learning, challenge-based learning, engagement, service learning, science outreach, design thinking, and mentoring.

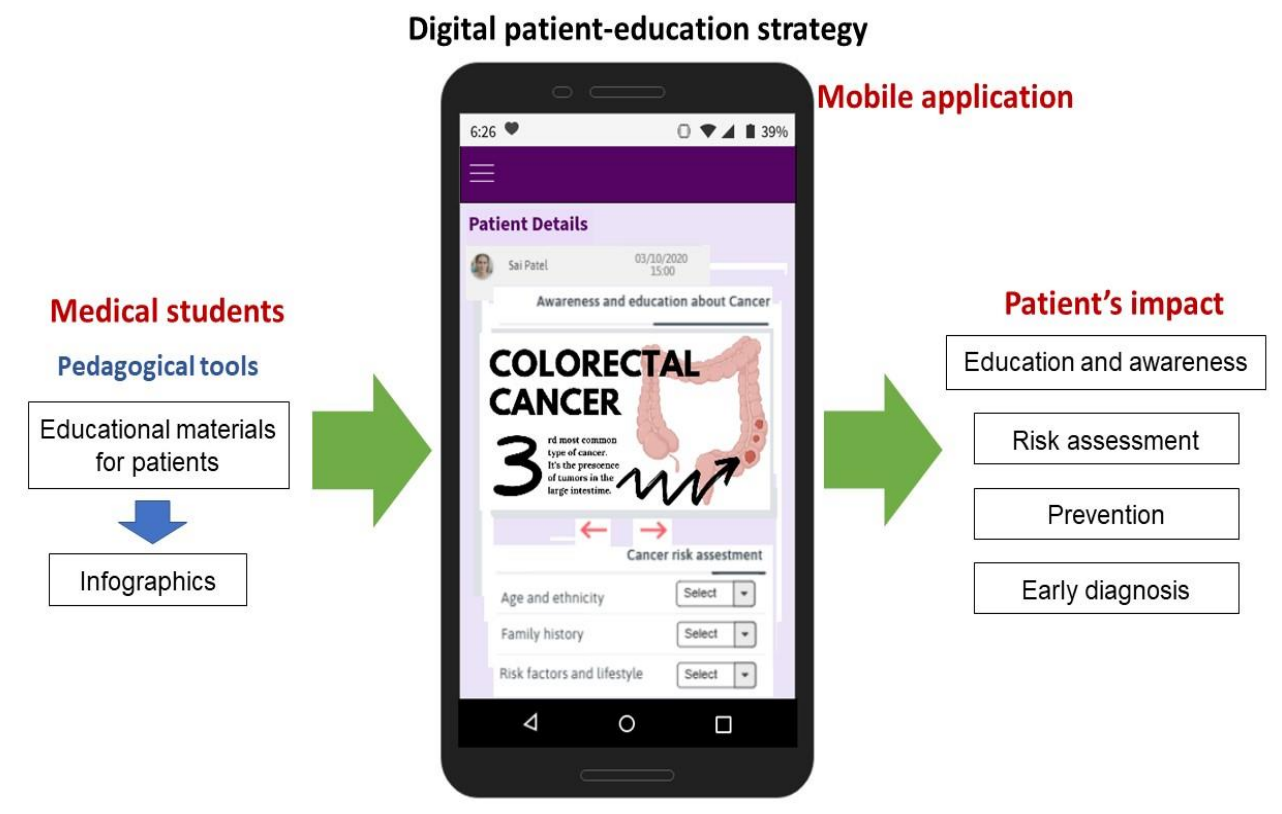

Figure 1: Diagram of the patient-education strategy involving undergraduate medical students and design of the mobile application.

\section{Methods}

Five undergraduate medical students enrolled in our institution (located in Monterrey, Mexico) from the Pathophysiology of Respiratory System course were recruited for the educational strategy. They agreed to participate voluntarily in the study and signed informed consent. We protected each student's identity and freedom of speech by avoiding using their names; instead, we labeled each collaborator as Participant A, B, C, etc. The mentioned strategy consisted of weekly digital sessions of 1.5 hours for four months where the students learned about the app's project, participated in the assigned tasks, and received feedback. The strategy's main objective was to create infographics about patient's education and awareness about cancer for the mentioned app. The infographics generation was an iterative process (design thinking), where the students received feedback and improved their infographics after each iteration. Two infographics about a different type of cancer were assigned per student to accomplish ten educational materials. The software used for the design of these materials were Piktochart, Canva, and PowerPoint.

${ }^{1}$ Non-Communicable Diseases (NCD) are those which are not transmissible directly from one person to another, such as heart disease, stroke, diabetes, chronic lung disease and cancer (WHO, 2016). 
This study used a qualitative approach with a descriptive and transversal design. At the end of the implementation, an online focus group session in English of 1.5 hours with the students' participation was used as an instrument for collecting information about the pedagogical experience. The conversations were motivated in the focus group using trigger questions. A video of this session was recorded, and a transcription of the student's interventions was obtained. Afterward, this video was analyzed to assess the educational strategy and its scopes, considering as categories: project-based learning, challenge-based learning, engagement, service learning, science outreach, design thinking, and mentoring. The digital platform used for the weekly sessions was Google Meet, while the focus group was recorded using Zoom.

\section{Results}

After four months of the educational strategy's implementation, each student generated two infographics. As a result, the objective of creating ten educational materials for the app was accomplished. One of these infographics is shown in Figure 2:
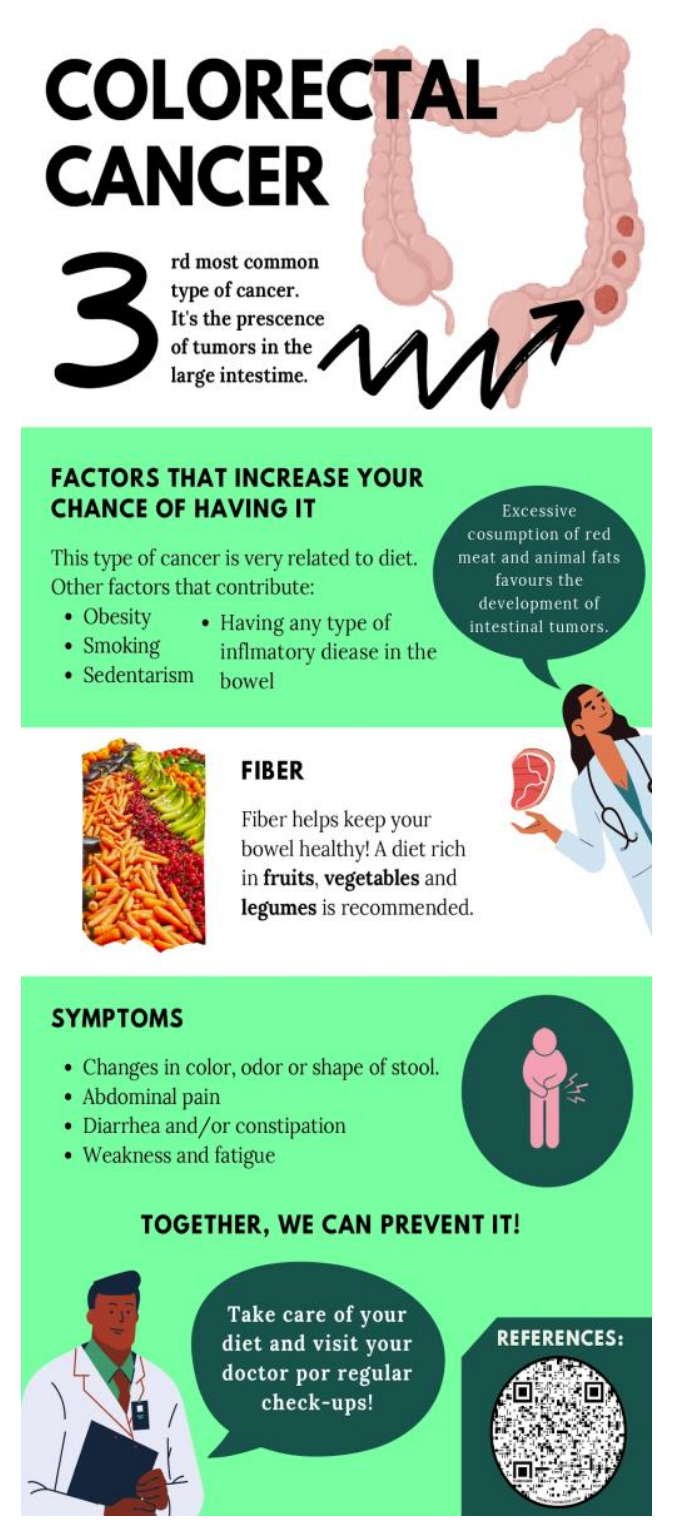

Figure 2: Example of infographics about colorectal cancer created by the students. 
During the focus group, the students were asked about: their motivations to join the educational strategy; the most relevant skills and new knowledge they acquired (in pedagogical, technical, and ethical terms); the effects of COVID-19 pandemic on their learning process; the obstacles and difficulties they faced; and what did they think about the social impact of the project or its contributions, in regards of expanding the possibilities of science outreach. At first, the students declared that they got involved in the project after finding professional, emotional, and social motivations, like reaching more patients and improving their creative abilities. Later, they explained that imaging and producing an infographic brought some relevant learning on communication, digital competencies, and writing expression. They also pointed out that the most demanding challenges to overcome were synthesizing a lot of information, operating graphic design software, and researching medicine and design thinking topics. After that, they talked about the COVID-19 pandemic, concluding it was not difficult for them to work under confinement or using digital devices because they have adapted to online classes and teamwork for almost a year. Finally, the students talked about their infographics' social impact, explaining that the project is a way to break barriers between the medical community and the non-expert audiences. According to the participants, infographics enforce the culture of prevention, bring clear information without scientific or complex terms, and reach many people simultaneously.

\section{Discussion}

After questioning the focus group participants about their motivations for joining the project, they pointed out their aim to help many patients in the future. Also, they mentioned the opportunity to develop new educational material accessible for anyone and the possibility of complementing medical knowledge with additional skills, such as creativity and information synthesis. According to Taylor and Parsons (2011), student engagement is not always merely academic but also institutional, behavioral, emotional, or relational. When referring to student engagement, these authors consider three relevant aspects: the initial need of scholars to belong to an initiative, their motives for showing dedication, and the reasons for final success. In our project, students committed themselves, above all, to get new proficiencies for their future as doctors - an intellectual, professional, and practical incentive-, and searching for the benefit of non-specialized convalescents - a social motivation-. Besides, they commented that their professors' enthusiasm, career path, and initial mentoring were key in their decision to participate, showing the importance of positive affections in enforcing student engagement, such as relish, confidence, or admiration.

Project-based learning is a constructivist technique of apprenticeship, sustained in understanding problems, actors, and circumstances (Krajcik and Blumenfeld, 2002). While participating in the digital app project that involved infographics creation for a non-specialized audience, students developed communication abilities such as concision, simplicity, and didacticism. "We had to break barriers between medical professionals and the general population," told one of our students (Participant A). The visual discourse needed to be attractive enough to target a broad diversity of hospital visitors and inmates. The tone, images, data, and text distribution in each infographic were strategically planned and selected. The students concluded the project triggered significant reflections on ethics, considering values like honesty, truth, empathy, or trust in the labor of medical science outreach. A student, Participant B, said: "The project's objective was to make a call to action to prevent the mentioned disease. Also, we wanted to end paternalism in medicine, encourage patients' responsibility, and promote self-taught education." 
The students had to overcome academic obstacles. Some of them, as Participant C, established that they "had to process a lot of information in a short time and only choose the most relevant facts." At the same time, they discovered it was uneasy to explain diseases and treatments without using medical terms and academic research difficulties, such as quoting correctly, respecting the copyright in graphics, or adapting scientific information to a brief format. Additionally, they had to quickly grow their learning curve in artistic and informatics disciplines, away from medicine. Most of the students had never used illustration or animation software before and had no graphic design experience, so they agreed that the project brought new knowledge. Challenge-based learning lets students concentrate their energy on solving outstanding issues and getting the exact skills they need (Johnston, Smythe, and Varon, 2009). Participants in this project learned about design-thinking, storytelling, semiotics, digital media language, and prototype management, regardless of acquiring new medical knowledge. Paraphrasing the words of a student, Participant D, technology was relevant in all the learning processes because "it had not been the same without computers or access to the Internet."

The focus group's reflections were curious because all students declared they had no significant problems due to the COVID-19 pandemic. They all had internet access to keep online contact or organize Zoom meetings to show their progress to the class and exchange ideas despite the quarantines. Participant B said that the project would have been more complicated if it required working per team, interviewing experts, testing the infographics' reception in potential patients, or involving external students. Nevertheless, the confinement became positive for some students, such as Participant E, who declared she could concentrate more on the research and design process while staying at home. Finally, the students said that the pandemic was not a complicated environment because they had adapted well to online sessions and remote work after almost a year of lockdown.

At last, the project participants talked in the focus group about the social impact of their infographics. They all said these materials enforced a culture of prevention, brought medical science closer to the average patient, and eradicated the barriers between experts and non-experts. Even so, there would be remaining problems to solve, such as showing these infographics to people without connectivity, reaching people with visual disabilities, or convincing the medical community to support initiatives like digital apps. After all, this project contributes to service-learning, which intends to use academic research and education to overcome civic problems, solve inequalities and transform societies (Felten and Clayton, 2011).

\section{Conclusion}

The actual pandemic has generated relevant challenges in medical students' education because faceto-face contact is highly restricted. However, digital technologies provide opportunities for the generation of learning experiences using novel pedagogical tools. This study explores an educational strategy where undergraduate students created infographics to improve patient awareness about cancer. The main objective of the intervention was accomplished, and ten of the mentioned educational materials were produced as a result. According to our focus group session, the pedagogical tools used in the mentioned strategy helped to create an engaging digital learning environment. As a result, the students improved their communication skills and knowledge about cancer and reflected on the importance of patients' interaction. Also, the students considered that they adapted well to the sessions and activities even though the interactions were online. The educational 
activities involving medical students in social projects have another beneficial outcome: positively impacting society's health. We expect to inspire educators to empower students to develop real-life solutions as part of their educational activities with this work.

\section{Acknowledgments}

The authors would like to acknowledge the financial support of Writing Lab, TecLabs, Tecnológico de Monterrey, Mexico, in the production of this work. Also, we acknowledge Emilia S. Núñez-Peña, Gabriela González-Escalante, Hannia M. Macías Cruz, Mónica S. Ponce-Rivera, and Sol P. GomezGarcía-Alvéstegui for their participation in the educational strategy. The first author was supported by the teaching assistant scholarship from its institution and the doctoral scholarship from CONACYT.

\section{References}

Baepler, P., Walker, J. D., Brooks, D. C., Saichaie, K., \& Petersen, C. I. (2016). A guide to teaching in the active learning classroom: History, research, and practice. Stylus Publishing, LLC.

Dunlap, J. C., \& Lowenthal, P. R. (2016). Getting graphic about infographics: design lessons learned from popular infographics. Journal of Visual Literacy, 35(1), 42-59.

Echevarria Zarate, J. (2008). Importancia de la detección temprana de cáncer. Revista Medica Herediana, 19(4), 135-137.

Felten, P. \& Clayton, P. (2011). Service-learning. New directions for teaching \& learning, 128, 75-84.

Johnston, F., Smythe, J., Varon, R. (2009). Challenge-Based Learning: An Approach for Our Time. Austin: The New Media Consortium.

Jones, N. P., Sage, M., \& Hitchcock, L. (2019). Infographics as an assignment to build digital skills in the social work classroom. Journal of Technology in Human Services, 37(2-3), 203-225.

Krajcik, J. \& Blumenfield, P. (2002). Project-Based Learning. In: Sawyer, K. (2002). The Cambridge Handbook of Learning Sciences. Massachusetts: Cambridge University Press.

Lafuente-Sanchez, J. V. (2019). El ambiente educativo en los contextos de formación médica. Educación médica, 20 (5), s. 304-308.

Martin, L. J., Turnquist, A., Groot, B., Huang, S. Y., Kok, E., Thoma, B., \& van Merriënboer, J. J. (2019). Exploring the role of infographics for summarizing medical literature. Health Professions Education, 5(1), 48-57.

Sanmarti Puig, N., \& Márquez Bargalló, C. (2017). Aprendizaje de las ciencias basado en proyectos: del contexto a la acción. Apice, 1(1), 3-16.

Taylor, L. \& Parsons, J. (2011). Improving student engagement. Current Issues in Education, 14(1).

Usmani, A., Omaeer, Q., \& Sultan, S. T. (2011). Mentoring undergraduate medical students: experience from Bahria University Karachi. JPMA-Journal of the Pakistan Medical Association, 61(8), 790 .

Valdez-García, J. E., Cabrera, M. V. L., Martínez, M. D. L. Á. J., Elizondo, J. A. D., Rivas, J. A. G. D., \& Olivares, S. L. O. (2020). Me preparo para ayudar: respuesta de escuelas de medicina y ciencias de la salud ante COVID-19. Investigación en educación médica, 9(35), 85-95.

World Health Organization (2016). Non-communicable diseases. https://www.who.int/healthtopics/noncommunicable-diseases\#tab=tab_1

World Health Organization (2021). Cancer. https://www.who.int/health-topics/cancer\#tab=tab_1 